
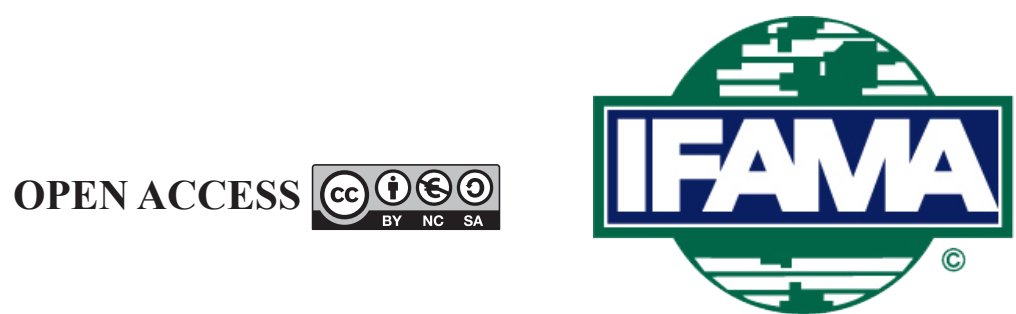

International Food and Agribusiness Management Review

Volume 24, Issue 5, 2021; DOI: 10.22434/IFAMR2020.0146

Received: 1 September 2020 / Accepted: 26 January 2021

\title{
European private food safety standards in global agri-food supply chains: a systematic review REVIEW ARTICLE
}

\author{
Madhura Rao ${ }^{\circledR a}$, Aalt Bast ${ }^{\mathrm{b}, \mathrm{c}}$ and Alie de Boer ${ }^{\mathrm{d}}$ \\ ${ }^{a}$ PhD Candidate, ${ }^{d}$ Assistant Professor, Food Claims Centre Venlo, Campus Venlo, \\ Maastricht University, Nassaustraat 36, 5911 BV, Venlo, the Netherlands \\ ${ }^{b}$ Professor, University College Venlo, Campus Venlo, Maastricht University, \\ Nassaustraat 36, 5911 BV, Venlo, the Netherlands
}

cProfessor, Department of Pharmacology \& Toxicology, Faculty of Health, Medicine and Life Sciences, Maastricht University, Universiteitssingel 50, 6229 ER, Maastricht, the Netherlands

\begin{abstract}
Private food safety standards have become an important governance mechanism in contemporary food supply chains. While much has been written about private standards from the perspectives of different academic fields, there has never been a dedicated literature review to examine their interaction with global food supply chains. In this systematic review, 45 peer reviewed articles on private food standards, selected through extensive searches in four academic databases are critically appraised. Our analysis reveals that the most studied European private food safety standards are owned by retail conglomerates and therefore place the retail sector in a position of influence in the supply chain. These standards influence supply chain structures, market access, and the efficiency of food safety management systems. They also challenge the traditional relationship shared by actors in the supply chain with public authorities and the World Trade Organization. In the recent years, their scope has expanded to include topical issues such as environmental sustainability, worker safety, and animal welfare. Overall, the review suggests that European private food safety standards alter the operations of modern agri-food supply chains to accommodate consumer wishes while allowing the retail sector to exert its influence without taking on additional legal and economic liability.
\end{abstract}

Keywords: private standards, GlobalGAP, BRC, food safety, retail JEL code: F10, H70, L15, I18, Q17

\footnotetext{
${ }^{\circledR}$ Corresponding author: m.rao@maastrichtuniversity.nl
} 


\section{Introduction}

Food supply chains today can be best described as complex, dynamic, and more globalised than ever before (Fagotto, 2014; Lin, 2014). It is these characteristics that make it a challenging task for governments to regulate supply chains without the help of private actors (Lin, 2014). Various factors such as the need to bolster public law, facilitate international trade, and gain (and maintain) consumer trust have led to the proliferation of food safety standards created and enforced by private actors (Lin, 2014). While private standards can be used to influence various aspects of food production other than safety, safety concerns are seen as the reason for their birth.

When GlobalGAP (wherein GAP stands for Good Agricultural Practices), previously known as EurepGAP, was started in 1997, it was seen as a form of neo-liberal governance that introduced the idea of food safety being the combined responsibility of the State and private actors (Casey, 2011). Ever since, the European Union's regulation on food safety seems to have evolved while keeping in mind this responsibility shouldered by private actors. The EU General Food Law unequivocally places responsibility on the private sector; stating that food business operators have the primary legal responsibility for ensuring the safety of food (EC, 2002).

Of the various private standards that are widely adopted around the world today, several are incorporated in the European Union. Numerous scholars attribute the success of European private standards to the favourable relationship they share with the public law (Fagotto, 2014; Havinga, 2006; Lin, 2014). This review exclusively considers European standards in order to study the unique position held by private standards under EU law.

To our knowledge, there has never been a review that systematically brings together and synthesizes the extensive knowledge on the subject of private food safety standards. Such a review is important to this topic because of how diverse its current scholarship is. Our aim is to present an analysis of literature on private food safety standards belonging to different fields of study, to better understand their interaction with global agrifood supply chains. Results from this review have the potential to act as a steppingstone for future research on food safety regulation and international trade in agri-food supply chains. This paper reveals which aspects of private food safety standards have been studied extensively and which ones have been overlooked in current literature, thus paving the way for an organised approach towards filling existing knowledge gaps.

\section{Materials and methods}

In order to appraise existing research on the topic using explicit, accountable and rigorous methods, a systematic review was seen as the most suitable method. This method was chosen over other forms of literature review to limit the risk of researcher bias and offer the highest possible replicability (Petticrew and Roberts, 2008). Literature has been selected, included, and excluded based on transparent, predefined criteria. The systematic review guidelines published in the PRISMA-P statement (Moher et al., 2015) were used to produce this review.

\subsection{Search strategy and information sources}

This paper is a review of 45 peer reviewed journal articles that discuss European private food safety standards. Articles were retrieved through a systematic keyword search in December 2019 in four academic databases - Hein Online, Microsoft Academic, Science Direct, and Web of Science. Multiple databases, specialising in different fields, were used to ensure that the search was as comprehensive as possible. Each database search used Boolean operators to combine the three keywords - 'private standards', 'food safety' and 'Europe'. For Science Direct, additional keywords were used to include concepts closely related to private standards. This was done in order to yield more specific results and reduce the volume of extraneous literature. Using these synonyms on the other three databases did not improve the quality of the results. Therefore, only three keywords were used for searching the other databases. The query for all databases was limited to titles, abstracts, and keywords used in the articles. 
Three articles were included in the final list by identifying them from the reference lists of articles that met the eligibility criteria. Additional literature was retrieved by searching the academic database Google Scholar. Google Scholar was not used for the preliminary search because of the several limitations it presents in relation to systematic reviews (Anderson, 2013). However, for the sake of comprehensiveness, eight studies retrieved from Google Scholar that were of high relevance to this review and were not included in the results from the previous search in academic databases were chosen to be included.

\subsection{Eligibility criteria}

Abstracts of all results were read. In subsequent steps, articles were filtered out and excluded by applying seven exclusion criteria. In the first round (based on abstracts), articles were excluded if they: (1) lacked scientific rigour; (2) were in a language other than English; (3) focused on supply chains other than those of agriculture and food; (4) were not related to food safety; (5) were not about private standards; (6) were not specific to European private standards; or (7) focused on microbiology, toxicology, health, consumer science, or sustainability.

\subsection{Study selection}

The initial search produced 698 articles. After de-duplication, 576 articles remained. Abstracts of all identified articles were read, and exclusion criteria were applied. For the second round of exclusion, 86 articles remained and were read in full. Additional items were excluded by applying the exclusion criteria 3 to 7 applied in the first round. Figure 1 displays the search process as a flowchart.

This body of literature was supplemented by including relevant studies identified from the reference lists of selected articles.

All three authors carried out the preliminary literature search independently and assessed titles and abstracts against the exclusion criteria in the first round. Full text assessment and subsequent exclusion was carried out by the first author. The other two authors critically assessed whether these exclusions were justified. Literature retrieved from Google Scholar and reference lists were included in the review after an independent assessment by all three authors. Mendeley Desktop was used to manage all data throughout the study.

\section{Characteristics of the body of literature}

This section offers a description of the body of literature that was studied as a part of this review. Supplementary Table S1 provides a list of all 45 included studies.

\subsection{Distribution over time}

There were no restrictions on the time period while searching for literature. The studies included in this review were published between 2004 and 2019. Given that private standards are a relatively recent phenomenon, it is not surprising that scholars started taking interest in them only around 20 years ago. The number of publications peaked in 2013 and 2014, with close to $31 \%$ of the included studies being published in the two years. Number of publications in the years that followed present a downward trend.

\subsection{Subject areas}

Private food safety standards have been examined from the perspective of several disciplines, making their discourse a highly transdisciplinary one. In the supplementary material, we classify each study based on subject area. Several studies combine expertise from more than one discipline and have therefore been categorised accordingly. Economics was the most frequent subject area for included studies $(\mathrm{n}=21)$. This 


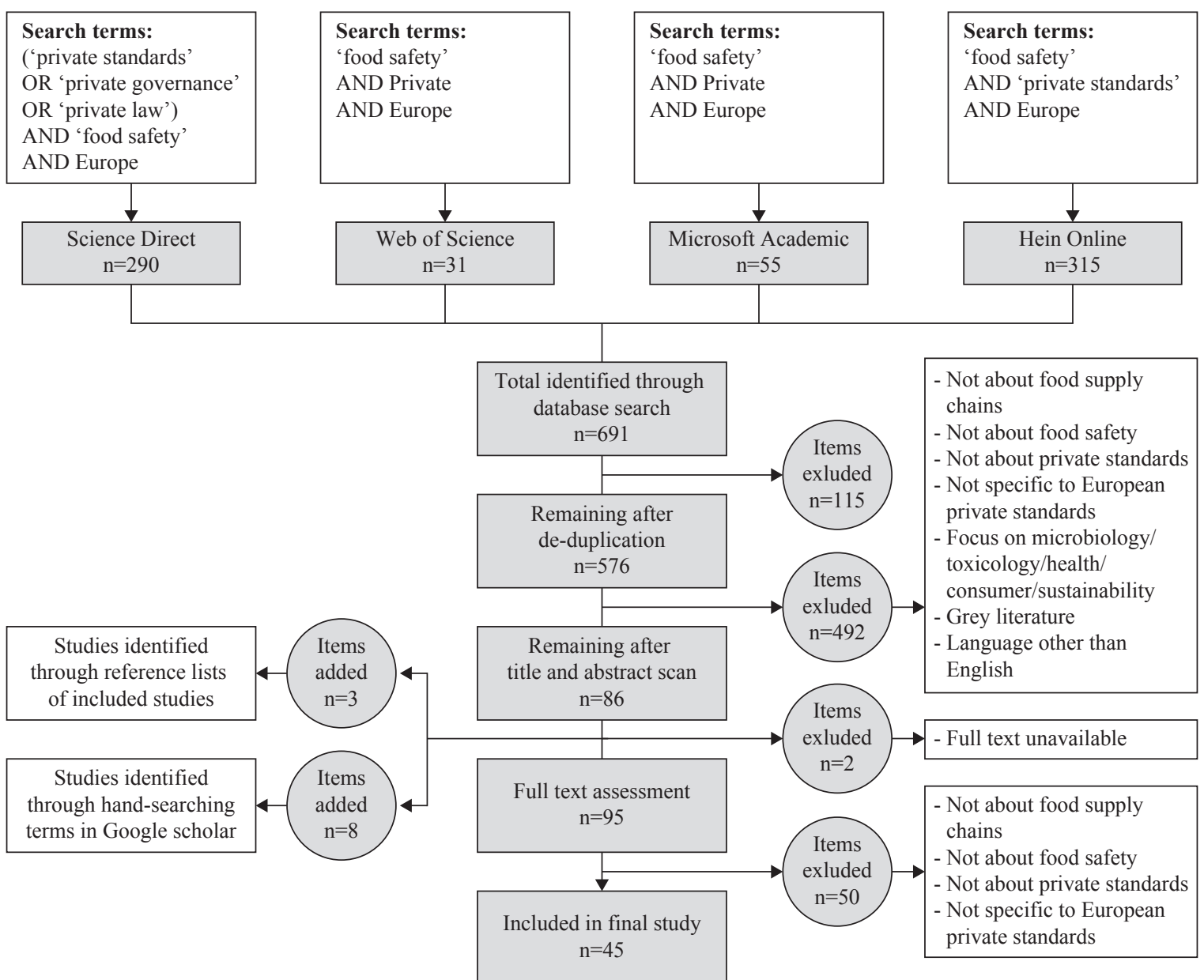

Figure 1. Data collection process flowchart.

number includes 2 studies that draw heavily from econometrics. The second most frequent category was law $(\mathrm{n}=15)$, with international trade law being the most popular subfield $(\mathrm{n}=7)$. This was followed by international development $(n=13)$, business and management $(n=9)$, governance $(n=7)$, and sociology $(n=6)$.

\subsection{Research methods}

The number of conceptual $(n=23)$ and empirical $(n=22)$ studies were almost equal. Conceptual studies were mostly from the fields of law, economics, and international development. Their study designs were typically based on legal analysis, application of existing theories, and the development of theoretical models. It is interesting to note that several conceptual studies suggest that there is a need for more empirical evidence on the subject.

Studies employing empirical methods analysed data from case studies, surveys, interviews, documents, and field observations. Among empirical studies, qualitative studies $(n=10)$ and quantitative $(n=9)$ studies were almost equal in number. Some included studies $(n=3)$ combine both approaches and have therefore been classified as mixed methods studies.

There were no observable differences in the topics or themes that were discussed in the conceptual and empirical studies. Therefore, observations, discussions, and conclusions presented in this review draw equally from both kind of studies. 


\subsection{Specific private schemes discussed}

The most frequently discussed private scheme was Global GAP, with 30 out of 45 studies focusing on it to varying degrees. This number includes studies on EurepGAP (GlobaGAP's official name prior to 2007) and regional adaptations of GlobalGAP (such as JGAP and ThaiGAP). Out of these 30 studies, ten focused exclusively on GlobalGAP, while others discussed other private schemes alongside GlobalGAP. The next most studied scheme was the British Retail Consortium (BRC), with 14 studies focusing on this private standard. Of these, only two focused exclusively on BRC. Other trans-national schemes discussed include GFSI $(n=11)$, followed by IFS ( $n=7)$, FSSC2200 ( $n=2)$, and Aquaculture Stewardship Council $(n=1)$. It is important to note that the Global Foods Safety Initiative (GFSI) is a private standard that benchmarks other private food safety standard, making it a meta-regulator and not a private food safety scheme in itself. National schemes and operators discussed in literature include Qualitat und Sicherheit (Germany) and Red Tractor Alliance (UK), with each standard studied in only one article each.

\subsection{Classification of private standards}

The included literature presented several different classifications of private food safety standards. Some scholars do not differentiate standards beyond the nature of their governance, i.e. public and private. However, many others go on to classify private standards based on scope, geographical reach, nature of the founding organisation, and other characteristics. Standards have been classified as mainstream and niche (Burrell, 2011), horizontal and vertical (García et al., 2004), legally-mandated and voluntary (Henson and Humphrey, 2010), post-farm gate and pre-farm gate (Soon and Baines, 2013), collective and business-specific (Henson, 2008) among others. Several of these have some common characteristics. However, since studies from different disciplines focus on different aspects of the standards and examine their impact based on unique classification systems, applying findings universally is difficult. It also makes it challenging to identify which kind of standards have been discussed more frequently and which ones have not yet been studied extensively. Supplementary Table S2 presents the various classifications used in literature.

\section{Thematic findings}

This section presents a synthesis of the various recurrent themes recognized from the literature. For each of the seven identified themes, prominent arguments and observations are presented as they are raised in the literature and do not necessarily reflect our personal views. Themes were identified using in vivo coding wherein the first and third author coded the included studies individually and grouped overlapping codes to form larger themes. Ultimately, power imbalance, increased vertical coordination, improved market access, food safety management, relationship with the World Trade Organization (WTO) and public authorities, and influence on attributes other than food safety were identified as themes that were recurrently discussed in literature. Most papers discussed multiple of these themes. The supplementary material mentions three key concepts discussed in each study.

\subsection{Power imbalance}

Power imbalance is created as a result of asymmetric business relationships, wherein one party can disproportionately influence the behaviour of the other parties involved. Power is exercised by stronger parties through interventions and sanctioning practices laid down as part of private rules that govern asymmetric business relationships (Rindt and Mouzas, 2015). The retail versus producer dynamic and the developed importing country versus developing exporting country dynamic were the two main phenomena discussed in this context. Several studies indicated that actors at the intersection of the two phenomena, i.e. producers in developing countries looking to export their products to retail in developed importing countries, were in the most disadvantageous position (García Martinez and Poole, 2004; Handschuch et al., 2013; Hansen and Trifković, 2014; Henson et al., 2011; Narrod et al., 2009; Jaffee and Masakure, 2005; Kersting and Wollni, 2012; Marschke and Wilkings, 2014; Rincon-Ballesteros et al., 2019; Schuster and Maertens, 2013; Subervie 
and Vagneron, 2013). There seems to be a consensus about European private standards demanding heavy investments in the form of annual fees, infrastructure and technology upgrades, training requirements, and third-party audits to bring safety and quality standards of products from third countries at par with, and often well above regulatory requirements and consumer expectations in the EU (Burrell, 2011; Herzfeld et al., 2011; Lin, 2014). These demands act as barriers to market entry for small and medium-sized producers, especially in developing countries. The consolidation of supermarket chains, with the five biggest retailers controlling a sizable majority of the European market, has an important role to play in retail being able to exercise its buying-power and impose private standards on suppliers (Fagotto, 2014).

Another aspect of power imbalance discussed in the literature is the participation of actors from developing countries in the decision-making process. Most widely adopted European standards claim to be democratic multi-stakeholder initiatives. Fuchs et al. (2009) and Hachez and Wouters (2011) make a detailed investigation on whether popular private standards are truly democratic and transparent in their decision-making process. Their results reveal that actors from developing countries, especially those that are geographically distant from Western Europe, face asymmetries in access and influence in the development of private standards. This also translates into standard owners not being held accountable by actors who are unfavourably impacted by private standards because they are not represented in the decision-making body in the first place. Within this group of developing countries, some seem to face more serious impediment than others. Herzfeld et al. (2011) observe a positive correlation between a country's standard adoption ability and its status as a former colony, familiarity with European languages, and historical trade relations with European countries. This leaves producers in developing countries without historical relations with European countries in an exceedingly disadvantageous position.

Even producers that can invest in adopting private standards are challenged by the disproportionate power of retail. For instance, Thompson and Lockie (2013) show that adopting private standards leads to producers forsaking aspects of management control and flexibility to simply stay in the market.

\subsection{Increased vertical coordination}

Vertical coordination is the process of ensuring that each successive stage in a value chain is interrelated to the next. The development of vertical coordination is a result of wanting to efficiently communicate about what to produce and how much to produce; from the consumer to the producer. Vertical coordination can be of varying degrees, ranging from informal alliances between actors to full-fledged vertical integration wherein a single organisation controls several stages of the supply chain. While various technological, regulatory, and socio-economic drivers promote vertical coordination in agri-food supply chains, private standards seem to play an important role as well (Hobbs and Young, 2000).

Improved traceability is a central premise of private food safety standards (Rincon-Ballesteros et al., 2019). To achieve this, exporters (traders), processors, and producers (farmers) have to work in collaboration to ensure the safety and integrity of the product throughout the supply chain. Relationships in agri-food supply chains have evolved from being purely transactional to becoming more cooperative (Busch and Bain, 2004).

For instance, García Martinez and Poole (2004) demonstrate that Morocco's fresh produce exporters have been able to achieve success as preferred suppliers in EU markets by adopting private standards because of intensive information sharing and vertical coordination in their domestic supply chain. In the same study, the authors elaborate on the Turkish fresh produce sector's preference to not establish strong vertical relationships which makes its position as an exporter relatively weak. This goes on to show that a lack of vertical coordination can negatively impact value chains where private standards are widely adopted.

Increased vertical coordination can bring about positive changes such as better control over the production process, improved reputation, enhanced sales margins, and knowledge and technology transfer for all actors involved (Handschuch et al., 2013; Jaffee and Masakure, 2005; Swinnen, 2016). However, when 
viewed in the context of the asymmetric relationships that exist in food supply chains, these vertical coordination efforts can be used by stronger parties to assert control. Rindt and Mouzas (2015) discuss vertically quasi-integrated supply chains where asymmetric relationships negatively impact the weaker actor. Quasi-integration is a type of vertical integration without a legal form, wherein stronger actors encourage various stages in the supply chain to integrate without themselves taking on any financial commitment or ownership. In such cases, the unintegrated but powerful actor often intervenes in the business of the weaker actor by means such as acquiring access to quality records, examining financial reports, and dictating upstream processes. The European retail sector encourages vertical coordination in upstream actors via private standards but prefers to not take on the added risk of ownership that comes with vertical integration (Busch and Bain, 2004).

\subsection{Market access}

While the trade inhibiting effects of private standards, especially on smallholders, have been widely discussed in literature (Henson, 2008; Henson et al., 2011; Shepherd and Wilson, 2013), some scholars propose that private food safety standards are an essential common language that bridges the gap between consumers and international suppliers ( $\mathrm{Du}, 2018)$. Several of the included studies offer insights on how adopting private food safety standards paves the way for producers to participate in international supply chains that would have otherwise been inaccessible to them (Du, 2018; Fulponi, 2006; Handschuch et al., 2013; Hansen and Trifković, 2014; Hatanaka et al., 2005; Rossignoli and Moruzzo, 2014; Swinnen, 2016).

In theory, improved market access positively correlates with higher income. However, there is a paucity of empirical studies to substantiate this. Results from a case study that focuses on the impact of private standards on Chilean raspberry farmers suggest that adopting private standards improves incomes by increasing yields and product quality and not because of improved market access (Handschuch et al., 2013).

\subsection{Food safety management}

Some studies suggest that private standards translate into improved food safety management systems (Jaffee and Masakure, 2005; Rincon-Ballesteros et al., 2019). A food safety management system goes beyond the physical safety-related attributes of food products and includes aspects such as record-keeping, chemical safety infrastructure, occupational health and safety, and technical training. On the one hand, it is hypothesised that these improvements can lead to higher domestic food safety in producing developing countries (Jaffee and Henson, 2004 in Fuchs et al., 2009). On the other hand, critical scholars believe that it only leads to an increased quality gap between exported and domestic products (Fuchs et al., 2009).

Therefore, there is no consensus on whether improved food safety management systems benefit only the retail sector and consumers in developed countries, or whether their spill over effects benefit producers and consumers in developing countries as well. As summarised by Herzfeld et al. (2011), benefits like enhanced internal processes and higher stability of supplier-customer relationships are difficult to quantify and analyse.

\subsection{Relationship with the World Trade Organisation}

Discussions about the WTO's role in regulating private food safety standards find a prominent place in literature. St. Vincent and the Grenadines' complaint to the WTO against the non-tariff trade barriers imposed by GlobalGAP (and in turn, the European Union) in 2005 is often viewed as a pivotal case when discussing the WTO's stance on private standards (Du, 2018; Hobbs, 2010; Maidana-Eletti, 2014; Mavroidis and Wolfe, 2017). The European Community argued that it could not be held liable for GlobalGAP's actions since it was not an official body of the European Community and by extension, did not fall under the WTO's jurisdiction (Du, 2018). 
In the broadest sense, the role of the Sanitary and Phytosanitary Measures (SPS) Agreement is to ensure a balance between WTO members' right to protect citizens' health and the need to prevent protectionism under the pretext of adhering to the SPS regulation. Therefore, if private standards do not present any objective evidence indicating that they are motivated by protectionist intentions, they do not fall under the purview of WTO law (Du, 2018). Some included studies also analysed whether private food safety standards fell under the purview of the WTO's Technical Barriers to Trade Agreement (TBT Agreement) (Bessel et al., 2006; Du, 2018; Henson, 2008; Maidana-Eletti, 2014; Mavroidis and Wolfe, 2017). Public standards concerning issues such as food labelling, packaging requirements, production and processing methods, fall under the aegis of the TBT Agreement. However, since private standards are not mandated by the State, extending the TBT Agreement's scope to them is difficult as well (Du, 2018; Hobbs, 2010; Maidana-Eletti, 2014)

Mavroidis and Wolfe (2017) propose that through a 'reference paper', the WTO should engage in a plurilateral negotiation that aims to increase the transparency of private standards and encourages its members that host these private standard setting organisations to 'discipline their subjects'. The proposed paper would be a set of commitments regarding members' regulation of private standard-setting bodies in their jurisdiction (Mavroidis and Wolfe, 2017).

In the future, if governments make private standards legally mandated, then the WTO's jurisdiction might extend to private standards as well (Henson et al., 2011). However, at present, the two remain separate.

\subsection{Relationship with public authorities}

Although the WTO does not possess any mechanisms to challenge private standards, public regulations applicable in countries where the standards are incorporated can shape them to a certain extent. For instance, as per the European Regulation (EC) No 178/2002 (EC, 2002), the onus of ensuring that the food placed on the market is safe for consumption lies primarily with the operator. As put forth by Charlier and Valceschini (2010), this responsibility places business operators in a situation of regulatory uncertainty because the exact means to fulfil the regulatory requirements are not specified. This makes private standards an attractive instrument to cope with uncertainty. Opinion on the extent to which public authorities should monitor private standards is divided. On the one hand, some authors note that ensuring food safety should not be left to private firms because economic interests may over rule safety diligence for private actors (Havinga, 2006). On the other hand, it can be argued that public bodies should adopt a more laissez-faire approach towards private actors being in charge of food safety because private standards are dynamic and can rapidly adapt to on-ground requirements and help bridge gaps in legislation (Konefal et al., 2005; Rindt and Mouzas, 2015). However, an important argument against the credibility of private standards as compared to public legislation is the weakness in their enforcement. A company seeking to adopt a private standard hires the certification organisation itself. Unless meticulously monitored through an accreditation system, certifiers could develop a close relationship with the company and compromise the integrity of the inspection in hope of future cooperation (Albersmeier et al., 2009; Fagotto, 2014; Havinga, 2006; Henson and Humphrey, 2010).

Another aspect that invites contradictory opinions is the causal relationship shared by private standards and public legislation. One point of view is that private standards are put in place by powerful private actors to pre-empt the future adoption of public regulations in a manner that is favourable to them (Fagotto, 2014). Another view is that private food safety standards are framed in such a manner that they can be closely adapted to the regulatory activities of the government (Henson et al., 2011).

Verbruggen and Havinga $(2015,2016)$ introduce a third element into the debate: private meta-regulators. As per their analysis, private meta-regulation acts as a medium for streamlining different private standards and offers opportunities for public actors such as states and intergovernmental organizations to influence the development and promulgation of private standards. The Global Food Safety Initiative (GFSI) is a prominent meta-regulator for private food safety standards that sets the minimum requirements for food 
safety standards. The role of such an organisation is to improve efficiency and reduce costs of auditing and certification throughout the supply chain (Verbruggen and Havinga, 2016).

\subsection{Influence on attributes other than food safety}

Private food safety standards were established to achieve the retail sector's intention of translating consumer expectations for safe food into a set of rules for producers to follow. As consumer wishes evolve, so do private standards (Henson, 2008).

Safety is generally treated as non-competitive attribute by the food industry (Fagotto, 2014). As a result, the retail sector seeks to create product differentiation through other attributes. New 'hooks' for capturing consumer attention include issues related to environmental and social sustainability (Henson and Humphrey, 2010). Standards that focused mostly on food safety have expanded their scope to include rules on other topical issues. The example of the Global GAP standard is worth discussing here. Recent years have seen issues such as animal welfare and worker safety included in its scope (Burrell, 2011). However, values held in high regard by European consumers may not be seen in the same light in third countries where these standards are applied. For instance, Naiki (2014) found that GlobalGAP's idea of what 'good' agricultural practices were did not fully resonate with producers in Japan and the United States. To establish itself in the United States, GlobalGAP had to exclude non-safety related issues such as labour conditions from its certification process. However, the same study also examines the case of Thailand where in spite of contradictory views regarding non-safety related issues, the market had to accept the conditions laid down by GlobalGAP. Utilising their status as de facto mandatory in several third countries, popular private food safety standards are attempting to influence attributes other than food safety for the purpose of product differentiation and meeting consumer demands. While developed countries such as the United States and Japan can voice their disagreement, developing countries tend to accede (Naiki, 2014).

A positive effect of this need to create product differentiation is that it may encourage innovation in the food industry. Niche markets such as free range, organic, fair trade, locally produced, non-allergenic, and GMO-free are being developed by transnational supermarket chains and producers in third countries that did not previously have access to these new supply chains might be able to join them by adopting private standards (Hatanaka et al., 2005; Konefal et al., 2005; Trienekens and Zuurbier, 2008). However, rigid checklist-based enforcement of private standards might create bottlenecks for innovative supply chains with unique processes (Albersmeier et al., 2009).

Based on their study on the fresh produce sector in Kenya, Jaffee and Masakure (2005) suggest that private food safety standards may also have a positive influence on labour relations in the food supply chain. Due to stricter safety and quality requirements, employers are inclined to provide staff with specialised training and extended contracts (Jaffee and Masakure, 2005).

\section{Discussion}

In this systematic review, private food safety standards, especially those owned by retail, were found to further the already existing power imbalance in the agri-food supply chain. They encourage vertical co-ordination and efficient information exchange between all involved actors. Next to this, private standards seem to positively impact market access by providing new opportunities to actors who can afford to implement them. As for actors who cannot afford to implement private standards, opportunities to trade in the international market are diminished considerably. Several included studies also comment on how private standards influence the supply chain's relationship with public authorities and indirectly, with the WTO.

Overall, existing research finds that the influence of private food safety standards in agri-food supply chains hinges on a combination of multiple factors and is experienced by various parts of the supply chain differently. Based on our findings, we explore some topics that invite further deliberation. 


\subsection{Publication trend}

As seen in Section 3.1, the selected literature presents an erratic pattern in its publication over time. Private standards were developed and popularised in the late 1990s and early 2000s. Understandably, an interest in studying them is reflected in early and mid-2000s. With the exception of two years, publications present an upward trend from 2003 until 2014. While there is no overt explanation as to why the number of publications has dropped in the recent years, it could be hypothesised that the absence of major food safety scandals has resulted in reduced focus on the topic. With food safety not being a major reason for concern in recent years, the role of private actors in the food supply chain is being scrutinised in the context of emerging threats such as environmental sustainability and food fraud. Next to this, the topic of private standards has been incorporated into larger and more contemporary subjects such as corporate social responsibility, business ethics, and fair international trade.

\subsection{Other schemes}

As stated in Section 3.4, most literature focuses on a few international schemes. It is understandable that these schemes were chosen because they were among the first to be established and have been widely adopted, thus providing ample scope for empirical work. However, observations recorded in Section 3.4 also reveal a gap in literature with regard to the lack of empirical evidence about the impact of other types of food safety schemes. Based on some of the classification systems from literature, other schemes such as those that are operational at national or regional levels, those operated by organisations other than retails conglomerates, and those that are industry specific or niche must be studied in order to evaluate whether these schemes perform well in areas where international, retail-owned schemes do not.

Some of the articles included in this review touch upon topics such as how private schemes, when adapted to the market needs of the adopting country, are more successful and enjoy better participation. Other articles address pitfalls in international retail-owned schemes such as a rigid top-down approach, exclusion of production processes that are different from the norm, and difficulties in adoption due to language barriers. These issues appear to be typical of schemes developed by international retail collaborations. However, it is not possible to assess whether switching to a non-retail owned standard or modifying retail-owned standards to accommodate the salient features of other type of standards would be a possible solution. Non-retail owned standards can include producer owned standards, regional or national level standards, sector specific standards, or standards owned by trade unions and non-governmental organisation.

Studies focusing on producer-owned, regional, national, and public-private partnership standards are important to the overarching discussion about private food safety standards and must be examined more extensively. At the moment, literature on private food safety standards cannot answer several queries regarding whether alternative, non-retail owned private standards can perform better in areas such as affordability for producers, ease of trading with organisations employing comparable standards, and enforceability. In order to get a more complete understanding of how private food safety standards influence agri-food supply chains, it is important to examine standards other than popular ones such as GlobalGAP and BRC.

\subsection{Intermediate actors in the food supply chain}

Many food safety standards are applied to multiple actors along the supply chain because guaranteeing the safety of a product only at the farm gate is not adequate. After leaving the point of production, food products pass through several hands before reaching the end consumer. Most private standards impose food safety regulations, either directly or by collaborating with another private scheme, on all actors that come in contact with the product. This means that besides the farmer, several other intermediaries such as transportation businesses, traders, brokers, manufacturers, packaging, storage facilities, and even laboratories are subject to control by private food safety standards. 
In literature, the focus seems to be on farmers growing fresh produce, with 11 out of 45 studies discussing how these producers are affected by private food safety standards. Some studies briefly discuss 'exporters', but mostly in the context of their relationship with producers. Impact on retailers is discussed by some $(\mathrm{n}=5)$ studies as well. Only one study (Rincon-Ballesteros et al., 2019) takes into account other actors such as food processors, butcheries, and catering. Several studies, especially conceptual ones, do not focus on any specific part of the supply chain and offer theories regarding how private standards interact with agri-food supply chain in general.

Therefore, in this review private standards are discussed largely in the context of producers and retailers. In order to assess how they exert their influence the entire chain, more empirical evidence focussing on intermediaries must be published.

\subsection{Relationship between private food safety standards and food waste}

Several studies confirm that private standards impose stricter and more prescriptive product specifications than EU law. The adverse effects of this have been discussed in some studies included in the review. Busch and Bain (2004) for instance, cite a study by Otsuki et al. (2001) indicating that increased stringency for contaminants such as aflatoxins can result in severe financial repercussions for African nations. Narrod et al. (2009) discuss how grape producers in India faced persistent consignment rejections by importing countries if the products did not meet the quality standards set by private schemes. Rejected consignments are often destroyed at the border or dispatched to a less demanding market (Hansen and Trifković, 2014). An Australian case study indicated that retailers might also use private standards to reject produce despite meeting specification if they are able to access cheaper produce elsewhere (Thompson and Lockie, 2013).

All of these studies focus largely on the economic and social repercussions of consignments of food products being rejected due to overly strict standards. Current literature does not provide evidence regarding what volume of food is destroyed or wasted for not meeting the inflated benchmarks imposed by private standards.

The pressure to feed an exponentially increasing population with finite resources has pushed food waste to the top of public and political agenda in recent years (European Court of Auditors, 2016). Both, the public and private sector have started recognizing it as a significant social, environmental, and economic problem (European Court of Auditors, 2016). The European Union, in line with the United Nations' sustainable development goals, is committed to reducing its food waste by $50 \%$ per capita by 2030 (EC, 2015). Based on the findings of this review, we posit that private food safety standards being important governance instruments in European food supply chains, have an impact on the state of food loss and waste. The REFRESH Project highlights that unfair trading practices as a result of unequal balance of power in the food supply chain are a cause of food waste (Bos-Brouwers et al., 2020). Another aspect to consider is whether the stringent nature of private standards acts as a barrier for surplus food and by-streams to be utilised to make new products.

Alternatively, it can also be speculated that private food safety standards help in preventing food waste. Various studies indicate that private standards help increase traceability, reduce product failure, identify and control food safety issues at an early stage in the production process, and reduce the chances of consignment rejection (Fagotto, 2014; Narrod et al., 2009; Rossignoli and Moruzzo, 2014). All of these can contribute towards reducing food waste. However, based on the current state of the literature, it is not possible to clearly establish how private food safety standards are related to food waste.

Further research on this topic could help examine the issue of food waste from a novel perspective. The fact that the European Commission views retailers as being in a favourable position to empower citizens, as consumers, to make sustainable environmental choices makes this prospect an especially exciting one (EC, 2008). 
Given that private food safety standards have already expanded their scope to include other sustainabilityrelated issues and the fact that food waste is becoming an increasingly prominent issue in society, our observation regarding the correlation between food waste and private standards might be of interest to actors in the food industry who are looking to move to a more circular system of production. For scholars and practitioners of futures studies and strategic management, it might be interesting to assess whether this correlation might present a weak signal.

\subsection{Limitations of the study}

Despite its best effort to provide a comprehensive résumé of the topic, this review presents some limitations. Firstly, studies in any language other than English were excluded from this review. Some of these could possibly be of high relevance and offer important insights on the topic.

Besides this, it was not possible to exclude studies that considered non-European standards alongside European ones. Excluding such studies would have resulted in an incomplete body of literature. We have ensured, to the best of our abilities, that results which were in the context of non-European standards were not reflected in this review. However, if the original studies presented common observations for European and non-European standards, it is possible that such combined observations are presented in this review as though they are solely in the context of European standards.

Some studies considered food safety standards and sustainability standards together. Given that standards which exclusively focused on food safety have diversified to include sustainability related themes, it was not possible to completely isolate the discussion on the two.

Lastly, few studies consider safety standards and quality standards together. Therefore, it is possible that some observations presented in this review the context of safety standards might actually be the consequences of quality standards. This is especially true when quality standards are considered as a part of safety standards.

Despite its several limitations, we believe that this review accurately reflects the state of the current literature by following standard systematic review procedures and presenting arguments and theories in a streamlined manner.

\section{Conclusions and implications}

This systematic literature review presents a critical appraisal of current literature on European private food safety standards and their interaction with agri-food supply chains around the world. Overall, we conclude that European private food safety standards exert considerable influence on global food and agricultural supply chains. In their pursuit to bring the safety standards of exporting countries at par with, and sometimes well above, EU legislation, they act as the link between consumer expectations and producers. Private standards also allow the retail sector to govern agri-food supply chains from a distance, without taking on additional legal or financial obligations. The most observable effects of private food safety standards are characterized by changes in governance patterns, supply chain structures, access to international markets, and increasing demands with respect to non-safety attributes of food products. While there is no litmus test to conclude whether private standards are beneficial or detrimental for global food supply chains, this paper hopes to further the discussion on the topic in a more systematic manner while shedding light on existing theories and evidence.

The review highlights areas that have not been extensively studied in the scholarship of private food safety standards. Future research on the subject could fill these gaps by focusing on topics such as the impact of small-scale and localised private food safety standards, the interaction of private standards with intermediate actors in the food supply chain, and the correlation between private food safety standards and food waste. 
This review provides insights for various relevant stakeholders in the agri-food industry about what the future of private food safety standards might look like. Professionals in the food industry might benefit from further investigating how potential trends such as meta-regulation, private standards impacting various quality attributes of food products, and changing supply chain structures might affect business. Lastly, insights from this review can aid policy makers and relevant bodies of governmental and intergovernmental organisation. Our elaboration on how private standards influence the relationship shared by food businesses and public authorities, weaknesses in the enforcement of private standards, and the role of private standards as a tool to cope with regulatory uncertainty can help in the development of policies that help improve food safety while protecting vulnerable food businesses from the negative impacts of private standards.

\section{Supplementary material}

Supplementary material can be found online at https://doi.org/10.22434/IFAMR2020.0146

Table S1a. List of included studies: Empirical studies - mixed methods.

Table S1b. List of included studies: Empirical studies - quantitative.

Table S1c. List of included studies: Empirical studies - qualitative.

Table S1d. List of included studies: Conceptual studies.

Table S2. List of classification systems for private standards.

\section{Acknowledgements}

This research has been made possible with the support of the Dutch Province of Limburg.

\section{Conflict of interests}

The authors declare that there are no conflicts of interest.

\section{Funding}

This research did not receive any specific grant from funding agencies in the public, commercial, or notfor-profit sectors.

\section{References}

Albersmeier, F., S. Holger, J. Gabriele and A. Spiller. 2009. The reliability of third-party certification in the food chain: from checklists to risk-oriented auditing. Food Control 20(10): 927-935. https://doi. org/10.1016/j.foodcont.2009.01.010

Anderson, P. 2013. What's wrong with Google Scholar for 'systematic' reviews. Available at: http://etechlib. wordpress.com/2013/01/23/whats-wrong-with-google-scholar-for-systematic-reviews/

Bessel, K.M., J.E. Hobbs and W.A. Kerr. 2006. Food safety and private international law: liability, traceability and transboundary marketing. Journal of International Food \& Agribusiness Marketing 4438(1-2): 29-48. https://doi.org/10.1300/J047v18n01

Bos-Brouwers, H., S. Burgos, F. Colin and V. Graf. 2020. Policy recommendations to improve food waste prevention and valorisation in the EU. Wageningen UR, Wageningen, the Netherlands. Available at: https://library.wur.nl/WebQuery/wurpubs/fulltext/517005

Burrell, A. 2011. Good agricultural practices' in the agri-food supply chain. Environmental Law Review 13(4): 251-270. https://doi.org/10.1350/enlr.2011.13.4.251

Busch, L. and C. Bain. 2004. New! Improved? The transformation of the global agrifood system. Rural Sociology 69(3): 321-346. https://doi.org/10.1526/0036011041730527 
Casey, D. 2011. Three puzzles of private governance: globalgap and the regulation of food safety and quality. UCD Working Papers in Law, Criminology \& Socio-Legal Studies Research Paper No. 22/2009. https://doi.org/10.2139/ssrn.1515702

Charlier, C. and E. Valceschini. 2010. Food safety, market power and private standards an analysis of the emerging strategies of food operators. International Journal on Food System Dynamics 1(2): 103110. https://doi.org/10.18461/ijfsd.v1i2.122

Du, M.M. 2018. The regulation of private standards in the world trade organization. Food and Drug Law Journal 73(3): 432-464.

European Commission (EC). 2002. Regulation (EC) No 178/2002 of the European Parliament and of the Council of 28 January 2002 laying down the general principles and requirements of food law, establishing the European Food Safety Authority and laying down procedures in matters of food safety. Official Journal of the European Union L 31: 1-24.

European Commission (EC). 2008. Sustainable consumption and production and sustainable industrial policy action plan. Communication from the Commission to the European Parliament, the Council, the European Economic and Social Committee and the Committee of the Regions. European Commission, Brussels, Belgium. Available at: https://eur-lex.europa.eu/legal-content/EN/ TXT/?uri=CELEX\%3A52008DC0397

European Commission (EC). 2015. Closing the loop - an EU action plan for the circular economy. European Commission, Brussels, Belgium. Available at: https://www.eea.europa.eu/policy-documents/com2015-0614-final

European Court of Auditors. 2016. Combating food waste: an opportunity for the EU to improve the resource-efficiency of the food supply chain. Special report No 34. EU, Brussels, Belgium. https:// doi.org/10.2865/8374.

Fagotto, E. 2014. Private roles in food safety provision: the law and economics of private food safety. European Journal of Law and Economics 37(1): 83-109. https://doi.org/10.1007/s10657-013-9414-z

Fuchs, D., A. Kalfagianni and T. Havinga. 2009. Actors in private food governance: the legitimacy of retail standards and multistakeholder initiatives with civil society participation. Agriculture and Human Values 28: 353-367. https://doi.org/10.1007/s10460-009-9236-3

Fulponi, L. 2006. Private voluntary standards in the food system: the perspective of major food retailers in OECD countries. Food Policy 31: 1-13. https://doi.org/10.1016/j.foodpol.2005.06.006

García Martinez, M. and N. Poole. 2004. The development of private fresh produce safety standards: implications for developing Mediterranean exporting countries. Food Policy 29: 229-255. https:// doi.org/10.1016/j.foodpol.2004.04.002

Hachez, N. and J. Wouters. 2011. A glimpse at the democratic legitimacy of private standards - assessing the public accountability of GLOBALGAP. Journal of International Economic Law 14(3): 677-710. https://doi.org/10.1093/jiel/jgr026

Handschuch, C., M. Wollni and P. Villalobos. 2013. Adoption of food safety and quality standards among chilean raspberry producers - do smallholders benefit? Food Policy 40: 64-73. https://doi.org/10.1016/j. foodpol.2013.02.002

Hansen, H. and N. Trifković. 2014. Food standards are good - for middle-class farmers. World Development 56: 226-242. https://doi.org/10.1016/j.worlddev.2013.10.027

Hatanaka, M., C. Bain and L. Busch. 2005. Third-party certification in the global agrifood system. Food Policy 30: 354-369. https://doi.org/10.1016/j.foodpol.2005.05.006

Havinga, T. 2006. Private regulation of food safety by supermarkets. Law and Policy 28(4): 515-533. https:// doi.org/10.1111/j.1467-9930.2006.00237.x

Henson, S. 2008. The role of public and private standards in regulating international food markets. Journal of International Agricultural Trade and Development 4(1): 63-81.

Henson, S. and J. Humphrey. 2010. Understanding the complexities of private standards in global agri-food chains as they impact developing countries. Journal of Development Studies 46(9): 1628-1646. https://doi.org/10.1080/00220381003706494 
Henson, S., O. Masakure and J. Cranfield. 2011. Do fresh produce exporters in sub-Saharan Africa benefit from GlobalGAP certification? World Development 39(3): 375-386. https://doi.org/10.1016/j. worlddev.2010.06.012

Herzfeld, T., L.S. Drescher and C. Grebitus. 2011. Cross-national adoption of private food quality standards. Food Policy 36(3): 401-411. https://doi.org/10.1016/j.foodpol.2011.03.006

Hobbs, J.E. and L.M. Young. 2000. Closer vertical co-ordination in agri-food supply chains. Supply Chain Management 5(3): 131-142. https://doi.org/10.1108/13598540010338884

Hobbs, J.E. 2010. Public and private standards for food safety and quality: international trade implications. Estey Journal of International Law and Trade Policy 11(1): 136-152. https://doi.org/10.4324/97813157202345

Jaffee, S. and O. Masakure. 2005. Strategic use of private standards to enhance international competitiveness: vegetable exports from Kenya and elsewhere. Food Policy 30(3): 316-333. https://doi.org/10.1016/j. foodpol.2005.05.009

Jaffee, S. and S. Henson. 2004. Standards and agro-food exports from developing countries: rebalancing the debate. World Bank Policy Research Working Paper 3348. The World Bank, Washington, DC, USA.

Kersting, S. and M. Wollni. 2012. New institutional arrangements and standard adoption: evidence from smallscale fruit and vegetable farmers in Thailand. Food Policy 37(4): 452-462. https://doi.org/10.1016/j. foodpol.2012.04.005

Konefal, J., M. Mascarenhas and M. Hatanaka. 2005. Governance in the global agro-food system: backlighting the role of transnational supermarket chains. Agriculture and Human Values 22: 291-302. https:// doi.org/10.1007/s10460-005-6046-0

Lin, C.F. 2014. Public-private interactions in global food safety governance. Food and Drug Law Journal 69(2). https://doi.org/10.2139/ssrn.2309495

Maidana-Eletti, M. 2014. International food standards and WTO law. Deakin Law Review 19: 217-241. https://doi.org/10.21153/dlr2014vol19no2art435

Marschke, M. and A. Wilkings. 2014. Is certification a viable option for small producer fish farmers in the global south? Insights from Vietnam. Marine Policy 50: 197-206. https://doi.org/10.1016/j. marpol.2014.06.010

Mavroidis, P. and R. Wolfe. 2017. Private standards and the WTO: reclusive no more. World Trade Review 16(1): 1-24. https://doi.org/10.1017/S1474745616000379

Moher, D., L. Shamseer, M. Clarke, D. Ghersi, A. Liberatî, M. Petticrew, P. Shekelle, L.A. Stewart and Prisma-P Group. 2015. Preferred reporting items for systematic review and meta-analysis protocols (PRISMA-P) 2015 statement. Systematic Reviews 4: 1. https://doi.org/10.1186/2046-4053-4-1

Naiki, A. and P. Yoshiko. 2014. The dynamics of private food safety standards: a case study on the regulatory diffusion of GLOBAL G.A.P. International \& Comparative Law Quarterly 63(1): 137-166. https:// doi.org/10.1017/S0020589313000389

Narrod, C., D. Roy, J. Okello, B. Avendaño, K. Rich and A. Thorat. 2009. Public-private partnerships and collective action in high value fruit and vegetable supply chains. Food Policy 34: 8-15. https://doi. org/10.1016/j.foodpol.2008.10.005

Otsuki, T., J.S. Wilson and M. Sewadeh. 2001. Saving two in a billion: quantifying the trade effect of European food safety standards on African exports. Food Policy 26: 495-514. https://doi.org/10.1016/ S0306-9192(01)00018-5

Petticrew, M. and H. Roberts. 2008. Systematic reviews in the social sciences. systematic reviews in the social sciences. Blackwell Publishing Inc., Hoboken, NJ, USA. https://doi.org/10.1002/9780470754887

Rincon-Ballesteros, L., G. Lannelongue and J. González-Benito. 2019. Implementation of the Brc food safety management system in Latin American countries: motivations and barriers. Food Control 106: 106712. https://doi.org/10.1016/j.foodcont.2019.106715

Rindt, J. and S. Mouzas. 2015. Exercising power in asymmetric relationships: the use of private rules. Industrial Marketing Management 48: 202-213. https://doi.org/10.1016/j.indmarman.2015.03.018

Rossignoli, C.M. and R. Moruzzo. 2014. Retail power and private standards in the agri-food chain. Agroecology and Sustainable Food Systems 38(9): 1108-1124. https://doi.org/10.1080/21683565.2014.925530 
Schuster, M. and M. Maertens. 2013. Do private standards create exclusive supply chains? New evidence from the Peruvian asparagus export sector. Food Policy 43: 291-305. https://doi.org/10.1016/j. foodpol.2013.10.004

Shepherd, B. and N.L.W. Wilson. 2013. Product standards and developing country agricultural exports: the case of the European Union. Food Policy 42: 1-10. https://doi.org/10.1016/j.foodpol.2013.06.003

Soon, J. and R. Baines. 2013. Public and private food safety standards: facilitating or frustrating fresh produce growers? Laws 2(1): 1-19. https://doi.org/10.3390/laws2010001

Subervie, J. and I. Vagneron. 2013. A drop of water in the Indian ocean? The impact of GlobalGap certification on lychee farmers in Madagascar. World Development 50: 57-73. https://doi.org/10.1016/j. worlddev.2013.05.002

Swinnen, J. 2016. Economics and politics of food standards, trade, and development. Agricultural Economics 47: 7-19. https://doi.org/10.1111/agec.12316

Thompson, L.J. and S. Lockie. 2013. Private standards, grower networks, and power in a food supply system. Agriculture and Human Values 30(3): 379-88. https://doi.org/10.1007/s10460-012-9404-8

Trienekens, J. and P. Zuurbier. 2008. Quality and safety standards in the food industry, developments and challenges. International Journal of Production Economics 113: 107-122. https://doi.org/10.1016/j. ijpe.2007.02.050

Verbruggen, P. and T. Havinga. 2015. Food safety meta-controls in the Netherlands. European Journal of Risk Regulation 6(4): 512-524. https://doi.org/10.1017/S1867299X00005079

Verbruggen, P. and T. Havinga. 2016. The rise of transnational private meta-regulators. Tilburg Law Review 21(2): 116-143. https://doi.org/10.1163/22112596-02102003 